\title{
Submicroscopic malaria parasite carriage: how reproducible are polymerase chain reaction-based methods?
}

\author{
Daniela Camargos Costa ${ }^{1}$, Ana Paula Madureira ${ }^{2}$, Lara Cotta Amaral ${ }^{1}$, \\ Bruno Antônio Marinho Sanchez ${ }^{3}$, Luciano Teixeira Gomes ${ }^{3}$, Cor Jésus Fernandes Fontes ${ }^{3}$, \\ Jean Ezequiel Limongi ${ }^{4}$, Cristiana Ferreira Alves de Brito ${ }^{1}$, Luzia Helena Carvalho ${ }^{1 /+}$
}

\author{
${ }^{1}$ Centro de Pesquisas René Rachou-Fiocruz, Belo Horizonte, MG, Brasil ${ }^{2}$ Departamento de Bioengenharia, \\ Universidade Federal de São João Del Rei, São João Del Rey, MG, Brasil Universidade Federal de Mato Grosso, Cuiabá, MT, Brasil \\ ${ }^{4}$ Centro de Controle de Zoonoses de Uberlândia, Uberlândia, MG, Brasil
}

The polymerase chain reaction (PCR)-based methods for the diagnosis of malaria infection are expected to accurately identify submicroscopic parasite carriers. Although a significant number of PCR protocols have been described, few studies have addressed the performance of PCR amplification in cases of field samples with submicroscopic malaria infection. Here, the reproducibility of two well-established PCR protocols (nested-PCR and real-time PCR for the Plasmodium 18 small subunit rRNA gene) were evaluated in a panel of 34 blood field samples from individuals that are potential reservoirs of malaria infection, but were negative for malaria by optical microscopy. Regardless of the PCR protocol, a large variation between the PCR replicates was observed, leading to alternating positive and negative results in 38\% (13 out of 34) of the samples. These findings were quite different from those obtained from the microscopy-positive patients or the unexposed individuals; the diagnosis of these individuals could be confirmed based on the high reproducibility and specificity of the PCR-based protocols. The limitation of PCR amplification was restricted to the field samples with very low levels of parasitaemia because titrations of the DNA templates were able to detect $<3$ parasites $/ \mu L$ in the blood. In conclusion, conventional PCR protocols require careful interpretation in cases of submicroscopic malaria infection, as inconsistent and falsenegative results can occur.

Key words: malaria - PCR - reproducibility - submicroscopic infection

As countries progress towards malaria elimination, the need to detect submicroscopic infections is becoming increasingly important, as reservoirs of infected persons may result in transmission even without the manifestation of clinical illness (McMorrow et al. 2011). Since the 1990s, important progress has been made in the molecular identification and characterisation of Plasmodium parasites. Polymerase chain reaction (PCR)based diagnostic methods targeting the small subunit rRNA (18SSU rRNA) gene have had great impacts because they allow for the specific detection of the four major human Plasmodium species at densities several times lower than the limit of optical microscopy (OM) detection, the mainstay for malaria diagnosis (Snounou et al. 1993, Kimura et al. 1997, Win et al. 2002). The next methodological improvement was the introduction of the adapted kinetic PCR, also referred to as real-time (RT)

doi: 10.1590/0074-0276140102

Financial support: FAPEMIG, CNPq, FIOCRUZ/PAPES, PRONEX Malaria, $\mathrm{CNPq} / \mathrm{DECIT} / \mathrm{MS}$

DCO is a recipient of the scholarship from CAPES and LHC, CJFF and CFAB from CNPq.

+ Corresponding author: 1hcarvalho@cpqrr.fiocruz.br

Received 22 February 2013

Accepted 26 September 2013 quantitative PCR, which decreased the time spent on conventional PCR protocols and the risks of contamination, as well as allowed for large-scale analyses (Hermsen et al. 2001, Veron et al. 2009, Dormond et al. 2010). Although the application of PCR-based methods for the routine diagnosis of malaria remains a target difficult to achieve (malERA 2011), this technology has greatly impacted the fields of malaria epidemiology, chemotherapy and vaccine development.

While the specificity of the PCR results is guaranteed by the nature of the target and the primers and/or probes, the sensitivity can be highly variable, depending on which protocols are used and the population that is undergoing malaria diagnosis (Jelinek et al. 1996, Berry et al. 2005). Considering that the prevalence of malaria has been significantly reduced in some areas over the past decade, a critical issue is the accurate detection of asymptomatic individuals with microparasitaemic infections (Stresman et al. 2012). This challenge could adversely impact the study of malaria control if it remains unsolved. Unfortunately, the validity of the PCR-based detection methods has not been adequately assessed for asymptomatic or microparasitaemic individuals. Therefore, to investigate how reproducible the results of the PCR assays are in detecting submicroscopic malaria infection, we evaluated the performance of two wellestablished and distinct 18SSU rRNA PCR protocols nested-PCR (Snounou et al. 1993) and RT- PCR (Mangold et al. 2005) - against a panel of field samples from 
long-term residents of a rural malaria-endemic area in the Amazon where asymptomatic malaria infections often occur (Maciel 2011). Because comparing the two traditional PCR protocols was not the focus of the current paper, the methodological approach includes the use of nested-PCRas a gold standard, as suggested by others (malERA 2011) and RT-PCR as an additional protocol to strengthen the results.

\section{SUBJECTS, MATERIALS AND METHODS}

Panel of samples - In this study, we included 34 samples from long-term residents of an endemic Amazon rural community, Colniza, state of Mato Grosso (MT); subclinical malaria infections were characterised in this area during a detailed descriptive epidemiology study carried out between 2003-2009 (Maciel 2011). In that study, the parasitological and epidemiological data from seven consecutive years identified a small community, herein referred to as Colniza, where $55.91 \%$ of all malaria cases were subclinical. Consequently, malaria infection could not be excluded a priori in the individuals exposed to malaria in Colniza. Colniza is located inside the Amazon forest in the northwest of MT, roughly 1,200 $\mathrm{km}$ from the capital Cuiabá; Colniza can be accessed by two paved roads, which connect MT to the states of Amazonas (BR-174) and Rondônia (MT-206). The economic activities of this municipality are based mainly on wood extraction and livestock. Malaria is transmitted year-round with an Annual Parasitological Index (API) of 98.5 cases per 1,000 inhabitants (Maciel 2011). Samples were collected in this area in 2008 during a survey of asymptomatic patients in the area. The following eligibility criteria were included: (i) a minimum age of 15 years, (ii) the absence of pregnancy, (iii) a lifetime exposure to malaria in the Colniza area, (iv) no self-reported symptoms suggestive of malaria, such as fever, myalgia, chills or headache and (v) negative blood parasites by direct examination of Giemsa-stained thick blood smears. Although all samples were negative by OM, 14 out of $34(41 \%)$ samples were positive according to a malariaspecific nested-PCR (Snounou et al. 1993), which was performed later in our laboratory. Consequently, all of the Colniza samples were initially considered individuals who might have submicroscopic parasitaemia and may therefore be potential malaria carriers. As a positive control, we included 52 field samples from patients who sought care at a regional reference malaria laboratory (Julio Muller University Hospital, Federal University of Mato Grosso, Cuiabá) and whose thick blood smears were positive for malaria. Based on the OM results, the parasite densities of the positive controls ranged from high ( $>1,000$ parasites $\mu \mathrm{L} /$ blood, $\mathrm{n}=16$ ), to medium $(1,000-301 \mu \mathrm{L} / \mathrm{blood}, \mathrm{n}=16)$ and low parasitaemia $(100-$ 300 parasites $\mu \mathrm{L} /$ blood, $\mathrm{n}=20$ ). As a negative control, 20 blood samples from volunteers living outside of the endemic area were included; these volunteers had never been infected or exposed to the malaria parasites.

Ethics - The ethical and methodological aspects of this study were approved by the Ethical Committee of Research on Human beings from the René Rachou
Research Centre/Oswaldo Cruz Foundation (reports 07/2006 and 01/2009), according to the Resolution of the Brazilian Council on Health 196/96.

Blood examination - The Giemsa-stained thick blood smear technique was used for malaria diagnosis in all of the samples in the present study; during this examination, long-term experienced microscopists were in charge of examining the equivalent of $0.2 \mu \mathrm{L}$ of blood (roughly 100 microscopy fields). For quality assurance, each slide was examined by two microscopists who had over 10 years of experience in reading malaria slides; their proficiency was periodically evaluated by local/ regional quality assurance programs of the Brazilian Ministry of Health (MS). Parasite density was estimated as the number of parasites per microlitre of blood, in accordance with the standards of the MS.

Whole blood samples and preparation of the DNA template - At the time of the thick blood smear preparation, $5 \mathrm{~mL}$ of blood was drawn into sterile tubes containing ethylenediamine tetraacetic acid and aliquots $(1 \mathrm{~mL})$ of the whole blood were subsequently used to purify the templates for the PCR assays. Blood was stored at $-70^{\circ} \mathrm{C}$ until it was processed. Genomic DNA was extracted using a Qiagen genomic DNA purification kit (Puregene ${ }^{\circledR}$ ) (Gentra Systems, Minneapolis, MN, USA), according to the manufacturers' recommendations. The DNA was eluted in a $330-\mu \mathrm{L}$ volume ( $\cong 100 \mathrm{ng}$ of DNA $/ \mu \mathrm{L})$ and stored at $-20^{\circ} \mathrm{C}$ until it was used.

Nested-PCR - Samples were amplified using a nested-PCR protocol adapted from the original protocol described by Snounou et al. (1993); the same primers described in the original study were used in this study. Briefly, all PCR reactions were performed in $20 \mu \mathrm{L}$ volumes containing $250 \mu \mathrm{M}$ each oligonucleotide primer, $10 \mu \mathrm{L}$ of Master Mix (Promega) (0.3 units of Taq Polymerase, $200 \mu \mathrm{M}$ each deoxyribonucleotide triphosphates and $1.5 \mathrm{mM} \mathrm{MgCl}_{2}$ ) and $2 \mu \mathrm{L}$ of DNA ( $\cong 6 \mu \mathrm{L}$ of whole blood). The PCR assays were performed using an automatic thermocycler (PTC-100 ${ }^{\mathrm{TM}}$ v.7.0) (MJ Research Inc, USA) and the following cycling parameters were used: an initial denaturation at $95^{\circ} \mathrm{C}$ for $5 \mathrm{~min}$ followed by 24 cycles of annealing at $58^{\circ} \mathrm{C}$ for $2 \mathrm{~min}$, extension at $72^{\circ} \mathrm{C}$ for $2 \mathrm{~min}$ and denaturation at $94^{\circ} \mathrm{C}$ for $1 \mathrm{~min}$ followed by a final annealing incubation at $58^{\circ} \mathrm{C}$ for $2 \mathrm{~min}$ and extension at $72^{\circ} \mathrm{C}$ for $2 \mathrm{~min}$. The temperature was then reduced to $4^{\circ} \mathrm{C}$ until the samples were taken. The cycling parameters for the second round of PCR were the same as the first reaction, but instead 30 cycles of amplification were used. The amplified products were detected by ethidium bromide staining following agarose $2 \%$ gel electrophoresis (Invitrogen) and the species-specific fragment sizes were 205 bp for Plasmodium falciparum, 120 bp for Plasmodium vivax and $144 \mathrm{bp}$ for Plasmodium malariae. Because human DNA represents the majority of the DNA in the samples, a gene present in the $\mathrm{ABO}$ human system was amplified in the panel of samples to determine the quality control of the DNA extraction, as previously described (Olsson et al. 1998). 
$R T-P C R$ - Identification of the malaria parasite species was performed by RT-PCR amplification of the 18SSU rRNA gene, as previously described (Mangold et al. 2005); based on this protocol, a consensus pair of primers was used to amplify a species-specific region of the multicopy 18SSU rRNA gene. Briefly, each 20 $\mu \mathrm{L}$ reaction mix contained $2 \mu \mathrm{L}$ of genomic DNA $\cong 6$ $\mu \mathrm{L}$ of whole blood), $10 \mu \mathrm{L}$ of $\mathrm{Sybr}^{\circledR}$ Green PCR master mix (Applied Biosystems), $2.5 \mathrm{mM} \mathrm{MgSO}_{4}$ (final concentration) and $0.5 \mu \mathrm{M}$ of each primer (BioSynthesis). The PCR conditions consisted of an initial denaturation at $95^{\circ} \mathrm{C}$ for $10 \mathrm{~min}$ followed by 40 cycles of $90^{\circ} \mathrm{C}$ for 30 sec and $60^{\circ} \mathrm{C}$ for $30 \mathrm{sec}$; fluorescence acquisition was performed at the end of each extension step. After amplification, the melting curves were observed from the dissociation curves and those melting curve analyses, which were based on nucleotide variations within the amplicons, provided a basis for the accurate differentiation of the three plasmodia: $P$. falciparum, $P$. vivax and $P$. malariae. The amplification and fluorescence detection were performed using the ABI PRISM ${ }^{\circledR} 7000$ Sequence Detection System (Applied Biosystems). The range of melting temperatures $(T)$ for each Plasmodium was $74-76^{\circ} \mathrm{C}$ for $P$. vivax, $71-73^{\circ} \mathrm{C}$ for $P$. falciparum and $68-70^{\circ} \mathrm{C}$ for $P$. malariae.

Reproducibility of the PCR reactions - Initially, each DNA sample from the individuals who might harbour submicroscopic parasitaemia (Colniza; potential malaria carriers) were submitted to three PCR reactions. We amplified the 18SSU rRNA gene using nested-PCR, which is widely regarded as the "gold standard" for the PCR detection of malaria parasites (malERA 2011). Additionally, the samples were also submitted to a second PCR protocol (RT-PCR for the Plasmodium 18SSU rRNA gene). After this first round of PCR, the Colniza samples were considered positive or negative if all of the PCR results were consistent. For the discordant results, the samples were submitted to a second round of PCR,

\section{TABLE I}

Performance of polymerase chain reaction (PCR) protocols evaluated against a panel of reference samples with single or multiple assays realised per PCR protocol

\begin{tabular}{cc}
\hline Nested-PCR & RT-PCR \\
positive & positive \\
$\mathrm{n}(\%)$ & $\mathrm{n}(\%)$
\end{tabular}

Samples Parasites $/ \mu \mathrm{L}(\mathrm{n})^{a}$ Single $^{b}$ Multiple Single Multiple

\begin{tabular}{lccccc}
\hline Positive & $>100(52)$ & $51(98)$ & $52(100)$ & $51(98)$ & $51(98)$ \\
Negative & $0(20)$ & $0(0)$ & $0(0)$ & $0(0)$ & $0(0)$ \\
\hline
\end{tabular}

$a$ : parasitaemia as detected by optical microscopy; $b$ : single, the result of the first PCR reaction, and multiple, the results of three concordant PCR reactions. There were no statistical differences between results from single vs. multiple PCR assays or from nested vs. real-time (RT)-PCR for single vs. multiple reactions $(p>0.05)$. which included a re-amplification using the gold-standard nested-PCR protocol and two additional replicates of the RT-PCR method; this approach ensured that each discordant sample was retested at least three times by each PCR protocol. Afterwards, the discordant samples were classified as doubtful for malaria infection. For samples from patients with microscopically detectable parasitaemia (positive controls), a consensus result per protocol was based on the agreement between at least three PCR results.

Statistical analysis - A chi-squared analysis was performed to compare the nested and RT-PCR protocols and to compare the single vs. multiple reactions. The agreement between the different assays was evaluated using McNemar's chi-squared analysis and the kappa ( $\kappa)$ coefficient of agreement. A 5\% level of difference was considered significant.

\section{RESULTS}

Performance of the nested-PCR and RT-PCR protocols against a panel of reference samples - As an internal control, microscopically positive $(\mathrm{n}=52)$ and negative $(n=20)$ control samples were evaluated using the nested and RT-PCR methods (Table I). Both PCR protocols were specific as no positive results were obtained from the blood samples of the 20 malaria naïve volunteers. Regardless of the PCR protocol, PCR accurately identified $98-100 \%$ of the microscopy-positive samples; concerning the reproducibility of the PCR amplification, no significant differences were observed after retesting all 72 control samples (3-5 replicates per protocol). Additionally, for the Plasmodium species-specific identification, the results of both PCR protocols were highly reproducible and, in general, equivalent to those obtained by OM (Table II). As expected, the PCR protocols detected a number of mixed infections $(P$. vivax plus $P$. falciparum) that could not be detected by microscopy (Table II). The reproducibility of the PCR methods was confirmed using $\kappa$ statistics, which demonstrated that no difference was observed between the single and multiple PCR reactions or between the nested and RT-PCR protocols ( $\kappa$-values of 0.70-0.91; McNemar test, $\mathrm{p}>0.05$ ).

Evaluation of PCR performance for detecting submicroscopic malaria infections - Thirty-four samples from long-term residents of a rural Amazon community with frequent subclinical malaria infections (potential malaria carriers) were assayed using both PCR-based protocols. At the time of the blood collection, all of these individuals had a negative malaria thick blood smear, but 14 out of $34(41 \%)$ individuals were positive for malaria according to the nested-PCR assay, which was performed in parallel. To evaluate the reproducibility of the DNA amplification by the PCR-based protocols, each sample was submitted to three additional PCR reactions (nested and RT-PCR); to reach a molecular consensus, the discordant samples were re-amplified by additional PCR assays (Table III). Molecular consensus confirmed the submicroscopic malaria infection in seven $(21 \%)$ individuals and excluded this possibility in 14 samples (41\%). In $13(38 \%)$ samples, the PCR replicates led to alternating 
positive or negative results and these discrepancies probably reflect the limitations of the molecular methods at low levels of parasitaemia. Regarding the identification of the Plasmodium species, only two samples (917 and 930) were discordant; nested-PCR identified these samples as mixed infections, however these results were not confirmed by RT-PCR. On the other hand, no positive results were obtained from the blood samples from five malaria naïve volunteers (data not shown).

Of importance, the limitation of PCR amplification at low levels of parasitaemia was restricted to DNA from field samples because titrations of DNA templates obtained from the Plasmodium reference isolates or species-specific plasmid constructions could be detected at concentrations of less than three parasites $/ \mu \mathrm{L}$ of blood. Figs 1, 2 illustrate the end-point DNA titrations of the RT-PCR method, in which the DNA templates were obtained from cultured P. falciparum or from an artificially mixed infection obtained from highly-parasitaemic individuals infected with $P$. falciparum and $P$. vivax $(\cong 10,000$ parasites $/ \mu \mathrm{L}$ of blood). Similar results were obtained using the nested-PCR protocol (data not shown).

\section{DISCUSSION}

As part of the international effort to reduce the global incidence of malaria, it has been proposed that the treatment of asymptomatic carriers should be an essential tool for breaking the cycle of infection in some transmission settings (Ogutu et al. 2010). However, improved diagnostic tests are needed to reach this goal in order to accurately detect submicroscopic malaria infections. Although it has been claimed that PCR-based protocols are capable of detecting very low levels of parasitaemia, the reproducibility of these methods in malaria field samples has been largely underestimated. Here, the main goal was to analyse the reproducibility of the PCR-based protocols in detecting submicroscopic malaria infections. Therefore, field samples, not standard DNA templates, were used in this analysis because some, if not all, of the field samples may contain inhibitors that are not present in the standard DNA samples (Andrews et al. 2005, Harris et al. 2010). In this context, we selected the Colniza area due to the high frequency of subclinical malaria, which made it feasible to identify submicroscopic malaria infections. Following this protocol, we demonstrated that the traditional PCR amplification protocols might not be able to accurately and reproducibly identify potential submicroscopic malaria carriers. In fact, the PCR results were inconsistent in 13 out of the $34(\sim 40 \%)$ individuals, even after seven replicates of each DNA template (4 nested-PCR replicates and 3 RT-PCR replicates) were performed. These results were quite different from those obtained from the replicate samples of the microscopic positive patients, which could be confirmed with a high degree of reproducibility using both PCR-based protocols.

As in the endemic areas where the cost of diagnostic tests becomes a limiting factor, we decided to use the simplest and most economical format of RT-PCR in this study, which relied on the detection of the fluorescent reporter SYBR Green I. While the sensitivity of SYBR Green is similar to other RT chemistries, the specificity of the reporter may be misleading in some few cases due to variations in the amount of template (Parida 2008). In the present study, it was possible to rule out this potential limitation of the SYBR-based protocols because RT-PCR was $100 \%$ specific, with no positive results from the negative controls (naïve volunteers). Additionally, similar results were obtained with both the nested-PCR and RT-PCR methods, suggesting the low variability between these two assay platforms based on the 18SSU rRNA gene. It is important to emphasise that the reproducibility of the SYBR Green protocols could be due to variations in the $T_{m}$ that impact the melting curves, for example. However, this does not seem to be the case here, as the optimisation of the PCR reactions resulted in a very small variation in the $T m$ values. Additionally, based on our positive panel of samples, which included a wide-range of parasitaemia, the SYBR Green protocol was reproducible after multi-

TABLE II

Polymerase chain reaction (PCR) performance for the detection of Plasmodium falciparum and/or Plasmodium vivax at microscopically positive samples

\begin{tabular}{|c|c|c|c|c|c|}
\hline \multirow[b]{3}{*}{ Plasmodium species } & \multirow[b]{3}{*}{$\mathrm{OM}^{a}$} & \multicolumn{4}{|c|}{$\begin{array}{c}\text { Positive samples } \\
\mathrm{n}(\%)\end{array}$} \\
\hline & & \multicolumn{2}{|c|}{ Nested-PCR } & \multicolumn{2}{|c|}{ RT-PCR } \\
\hline & & Single ${ }^{b}$ & Multiple & Single & Multiple \\
\hline P. vivax & $41(79)$ & $40(77)$ & $40(77)$ & $40(77)$ & $40(77)$ \\
\hline P. falciparum & $11(21)$ & $9(17)$ & $10(19)$ & $10(19)$ & $10(19)$ \\
\hline Mixed & 0 & $2(4)$ & $2(4)$ & $1(2)$ & $1(2)$ \\
\hline Negative & 0 & $1(2)$ & $0(0)$ & $1(2)$ & $1(2)$ \\
\hline
\end{tabular}

$a$ : optical microscopy (OM), which included 52 samples positive at parasite density $>100$ parasites per $\mu \mathrm{L}$ of blood; $b$ : nestedPCR and real-time (RT)-PCR were carried-out as described in Subjects, Materials and Methods; single, the first PCR reaction, and multiple, the results of three concordant PCR reactions. 
ple repetitions. Finally, the low reproducibility for detecting submicroscopic parasitaemia was not exclusive to the SYBR green protocol, but was also observed with the gold-standard nested-PCR. In conclusion, we agree with others that protocols based on SYBR Green are more cost efficient in endemic areas than the alternatives that use internal fluorogenic probes (Moreira et al. 2013).
Concerning mixed-species infections, while the nested-PCR method identified five dual infections of $P$. falciparum and $P$. vivax, the RT method only identified two. Because the RT-PCR protocol used here was based on single consensus primers, this result suggests that the mixed infection was misidentified; however, this RTPCR protocol has been used to amplify mixed-malaria

TABLE III

Reproducibility of polymerase chain reaction (PCR)-based protocols among 34 long-term residents of an Amazon rural community who might harbour submicroscopic parasitaemia (potential malaria carriers) ${ }^{a}$

\begin{tabular}{|c|c|c|c|c|c|c|c|c|}
\hline \multirow[b]{2}{*}{ Code } & \multicolumn{4}{|c|}{ Nested-PCR } & \multicolumn{3}{|c|}{ RT-PCR } & \multirow{2}{*}{$\begin{array}{c}\text { Consensus result } \\
\mathrm{n}(\%)\end{array}$} \\
\hline & First & Second & Third & Fourth & First & Second & Third & \\
\hline 903 & NEG & NEG & NEG & ND & NEG & ND & ND & - \\
\hline 906 & NEG & NEG & NEG & ND & NEG & ND & ND & - \\
\hline 907 & NEG & NEG & NEG & ND & NEG & ND & ND & - \\
\hline 909 & NEG & NEG & NEG & ND & NEG & ND & ND & - \\
\hline 911 & NEG & NEG & NEG & ND & NEG & ND & ND & - \\
\hline 912 & NEG & NEG & NEG & ND & NEG & ND & ND & - \\
\hline 913 & NEG & NEG & NEG & ND & NEG & ND & ND & Negative, 14 (41) \\
\hline 918 & NEG & NEG & NEG & ND & NEG & ND & ND & - \\
\hline 920 & NEG & NEG & NEG & ND & NEG & ND & ND & - \\
\hline 922 & NEG & NEG & NEG & ND & NEG & ND & ND & - \\
\hline 923 & NEG & NEG & NEG & ND & NEG & ND & ND & - \\
\hline 934 & NEG & NEG & NEG & ND & NEG & ND & ND & - \\
\hline 935 & NEG & NEG & NEG & ND & NEG & ND & ND & - \\
\hline 936 & NEG & NEG & NEG & ND & NEG & ND & ND & - \\
\hline 902 & FV & FV & FV & ND & FV & ND & ND & - \\
\hline 904 & $\mathrm{~V}$ & $\mathrm{~V}$ & $\mathrm{~V}$ & ND & $\mathrm{V}$ & ND & ND & - \\
\hline 916 & $\mathrm{~V}$ & $\mathrm{~V}$ & V & ND & $\mathrm{V}$ & ND & ND & - \\
\hline 921 & V & $\mathrm{V}$ & V & ND & $\mathrm{V}$ & ND & ND & Positive, 7 (21) \\
\hline 924 & $\mathrm{~V}$ & V & V & ND & $\mathrm{V}$ & ND & ND & - \\
\hline 925 & $\mathrm{~V}$ & $\mathrm{~V}$ & $\mathrm{~V}$ & ND & $\mathrm{V}$ & ND & ND & - \\
\hline 929 & $\mathrm{~V}$ & $\mathrm{~V}$ & $\mathrm{~V}$ & ND & $\mathrm{V}$ & ND & ND & - \\
\hline 901 & M & NEG & NEG & NEG & NEG & NEG & NEG & - \\
\hline 908 & $\mathrm{~V}$ & NEG & NEG & NEG & V & NEG & NEG & - \\
\hline 915 & NEG & NEG & $\mathrm{V}$ & NEG & V & V & V & - \\
\hline 928 & NEG & NEG & $\mathrm{V}$ & NEG & NEG & NEG & NEG & - \\
\hline 919 & NEG & NEG & $\mathrm{F}$ & F & NEG & NEG & NEG & - \\
\hline 905 & $\mathrm{~F}$ & NEG & NEG & $\mathrm{F}$ & $\mathrm{F}$ & NEG & NEG & Doubtful, 13 (38) \\
\hline 910 & NEG & $\mathrm{V}$ & NEG & $\mathrm{V}$ & $\mathrm{V}$ & V & V & - \\
\hline 917 & NEG & FV & $\mathrm{FV}$ & FV & $\mathrm{V}$ & $\mathrm{V}$ & $\mathrm{V}$ & - \\
\hline 930 & FV & NEG & $\mathrm{FV}$ & NEG & $\mathrm{V}$ & $\mathrm{V}$ & $\mathrm{V}$ & - \\
\hline 926 & V & NEG & NEG & V & NEG & NEG & NEG & - \\
\hline 927 & NEG & V & V & $\mathrm{V}$ & NEG & NEG & NEG & - \\
\hline 932 & $\mathrm{~V}$ & $\mathrm{~V}$ & $\mathrm{~V}$ & ND & NEG & NEG & V & - \\
\hline 933 & $\mathrm{~F}$ & NEG & NEG & NEG & NEG & NEG & $\mathrm{F}$ & - \\
\hline
\end{tabular}

$a$ : initially, each sample was submitted to the first round of PCR [3 nested-PCR (gold-standard) and 1 real-time (RT)-PCR]. Samples with discordant results were resubmitted to a second round of PCR (1 nested-PCR and 2 RT-PCR). This approach allowed that discordant samples were classified as doubtful after being tested at least in triplicate by each PCR protocol. Results were indicated as positive by Plasmodium vivax (V), Plasmodium falciparum (F), Plasmodium malariae (M) and mixed infection by P. falciparum and P. vivax (FV). ND: not done; NEG: PCR negative for Plasmodium infection. 
infections (Mangold et al. 2005). Because a comparison between the PCR protocols was not the focus of this paper, further studies will be required to properly address this question.

The results concerning the poor performance of the PCR methods for the identification of submicroscopic malaria infections corroborate previous observations of the irreproducibility of parasite detection in samples with very low levels of parasitaemia (Singh et al. 1999). This result means that any PCR template diluted past a certain threshold copy number will experience large variations in amplification. The absence of amplification at very low levels of parasitaemia was not related to the DNA extraction protocol because, as an internal control, a sequence of the $\mathrm{ABO}$ human genome was amplified in all of the tested samples. Although relevant, this internal control did not exhibit the specific amplification difficulties derived from field samples with low amounts of parasite DNA. This inherent limitation of PCR amplification, previously described as the Monte Carlo effect (Karrer et al. 1995), has been widely underestimated (Stenman \& Orpana 2001, Soong \& Ladányi 2003). In fact, specific parasite PCR amplification at very low parasite densities may be hindered by several distinct factors, including the biological sample itself (Guescini et al. 2008), the concentration of human genomic DNA (Andrews et al. 2005), the scarcity of the template (Harris et al. 2010, Rosanas-Urgell et al. 2010), variations in the amplification conditions (Calderaro et al. 2007) and the PCR reagents, even when using premade master mixes from the same manufacturer (Bustin 2002).

Regarding the scarcity of the template, it is clear that the likelihood of detecting parasites present at very low levels decreases as the volume of blood analysed decreases. Thus, for the detection of submicroscopic in-

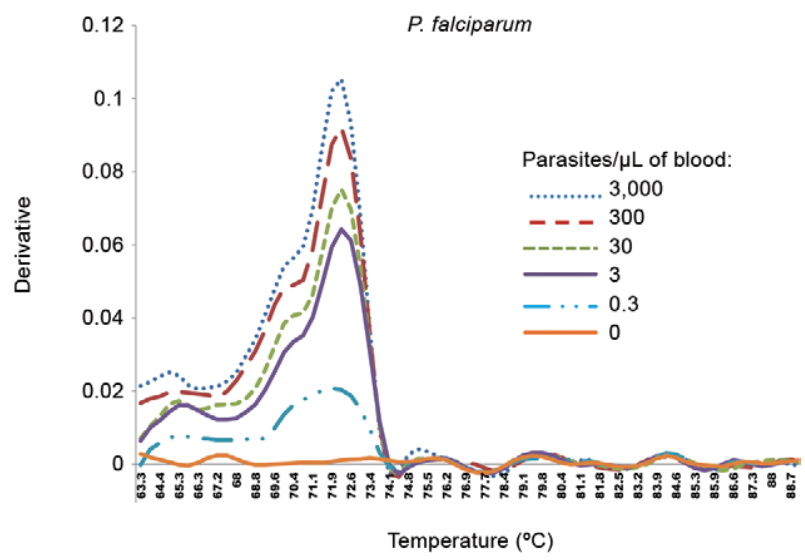

Fig. 1: real-time polymerase chain reaction melting curve analysis obtained from DNA template dilutions from Plasmodium falciparum continuous erythrocyte culture. The $P$. falciparum parasite (BHz 26/86), a chloroquine-resistant isolate (Carvalho et al. 1991), was maintained in culture by the candle jar method (Jensen \& Trager 1977), with cultures maintained synchronised as described (Jensen 1978). Serial dilutions of samples included were 3,000, 300, 30, 3, 0.3 and 0 parasite $\mu \mathrm{L}$ of blood. The graph was generated by using the ABI PRISM $^{\circledR} 7000$ Sequence Detection System (Applied Biosystems). fections, it has been proposed that the DNA templates to be analysed by PCR should correspond to at least 5 $\mu \mathrm{L}$ of the whole blood (Proux et al. 2011). In the current paper, to avoid this potential limitation, both PCR protocols were performed with $2 \mu \mathrm{L}$ of template, which corresponded to approximately $6 \mu \mathrm{L}$ of the whole blood collected from the patient. Because the use of templates isolated from substantially higher volumes of blood might encounter difficulties due to the high quantities of human DNA, blood filtration methods for the removal of leukocytes have been proposed to increase the PCR sensitivity during malaria vaccine clinical trials (Andrews et al. 2005, Bejon et al. 2006). After performing a multistep protocol, during which $5 \mathrm{~mL}$ of blood was filtered to remove the leukocytes, Andrews et al. (2005) established a PCR cut-off point of 20 parasites $/ \mathrm{mL}$ to follow the vaccinated volunteers in the Phase II trials. Taken together, these results mean that the most commonly used PCR methods might not accurately detect subclinical malaria infections. These findings could be particularly relevant when studying malaria in low transmission settings, where a negative PCR result may indicate that the individual is truly negative or may be a consequence of insufficient sensitivity of the PCR tests. At this time, it is not possible to differentiate between these two possible outcomes as the validity of PCR has not been adequately assessed for asymptomatic or microparasitaemic individuals (Stresman et al. 2012).

Although the results described here show a clear inconsistency of the PCR results in sub-patent malaria infections, the current results have limitations. The absence of similar studies performed with field samples makes it hard to compare our results with other researchers; in fact, the consistency of the PCR results in the submicroscopic carriers has never been properly assessed, especially in field settings where sample collection and storage may not be optimal (Stresman et al. 2012). Ad-

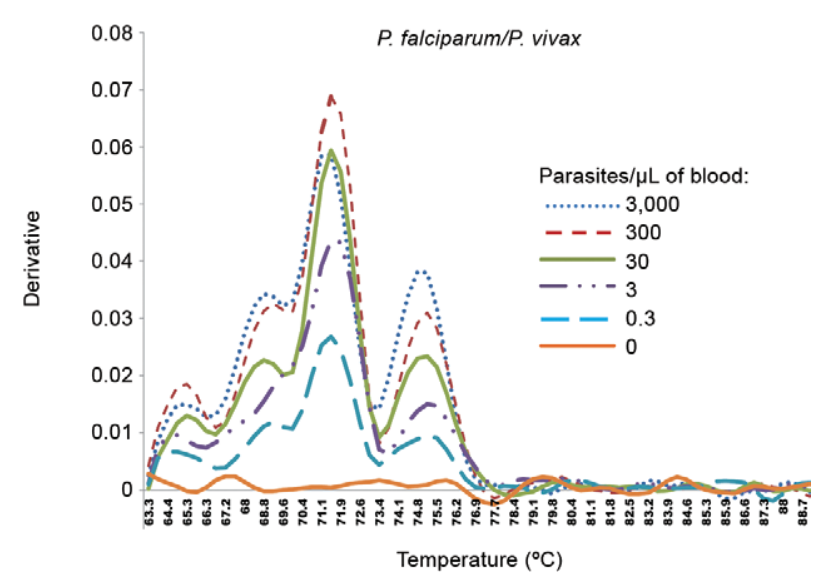

Fig. 2: real-time polymerase chain reaction melting curve analysis obtained from DNA template dilutions from and artificial Plasmodium falciparum and Plasmodium vivax infection. The graph was generated by using the ABI PRISM ${ }^{\circledR} 7000$ Sequence Detection System (Applied Biosystems). Serial dilutions of samples included were 3,000, 300, 30, 3, 0.3 and 0 parasite $/ \mu \mathrm{L}$ of blood. 
ditionally, the amplification of scarce DNA templates by any PCR-based protocol requires a very high standard of laboratory practice. Because we have well-trained and qualified personnel and we followed the requirements of the International Organization for Standardization/ International Electrotechnical Commission 17025, it was possible to minimise technical problems, such as those related to the adequate manipulation of the devices used in the PCR assays. Consequently, at present, the application of PCR-based methods is restricted to wellequipped laboratories with specially trained technicians. To develop new strategies to manage the parasite-negative individuals, PCR capacity building programs are underway in several African countries with the help of the Malaria Clinical Trials Alliance (malERA 2011). Unfortunately, an initiative of this magnitude has not yet been initiated in Latin America, where P. vivax is the predominant species.

It is critical to achieve a sufficient sample size when studying areas with sub-patent malaria infections in order to have an adequately powered study. In this context, the size of our sample set could not be increased in the Colniza area; the geographical access and political conflicts, which often affect the gold-mining areas of the Brazilian Amazon, hampered the continuation of our study there. Accordingly, the malERA initiative stated that sufficiently powered studies are difficult to implement in settings with low malaria prevalence and this challenge could adversely impact malaria control (malERA 2011). Regrettably, at the moment, this question remains unsolved.

In conclusion, our data show that conventional PCR protocols based on the 18SSU rRNA plasmodial gene do not allow for the accurate detection of submicroscopic malaria infections. Consequently, PCR results require careful interpretation when the population of interest includes microparasitaemic individuals. Currently, no PCR protocol is able to bypass the lack of PCR reproducibility at low levels of parasitaemia. Although some new protocols have promise, such as loop-attenuated isothermal amplification, these protocols have not yet been adequately tested in community-based studies or in the detection of low-density parasitaemia (Han 2013). Thus, studies are required to decrease the current limit of detection in the PCR assays in low-transmission settings. Furthermore, we agree with researchers that these protocols should be validated as a useful tool for the accurate detection of submicroscopic malaria infection, through comparative multicentre studies and this step is essential before these protocols are put into practice (Proux et al. 2011).

\section{ACKNOWLEDGEMENTS}

To the Program for Technological Development in Tools for Health, Fiocruz, for use of the real-time facilities.

\section{REFERENCES}

Andrews L, Andersen R, Webster D, Dunachie S, Walther R, Bejon P, Hunt-Cooke A, Bergson G, Sanderson F, Hill A, Gilbert S 2005. Quantitative real-time polymerase chain reaction for malaria diagnosis and its use in malaria vaccine clinical trials. Am J Trop Med Hyg 73: 191-198.
Bejon P, Mwacharo J, Kai O, Mwangi T, Milligan P, Todryk S, Keating S, Lang T, Lowe B, Gikonyo C, Molyneux C, Fegan G, Gilbert S, Peshu N, Marsh K, Hill A 2006. A Phase 2b randomised trial of the candidate malaria vaccines FP9 ME-TRAP and MVA ME-TRAP among children in Kenya. PLoS Clin Trials 1: 29.

Berry A, Fabre R, Benoit-Vical F, Cassaing S, Magnaval J 2005. Contribution of PCR-based methods to diagnosis and management of imported malaria. Med Trop (Mars) 65: 176-183.

Bustin S 2002. Quantification of mRNA using real-time reverse transcription PCR (RT-PCR): trends and problems. J Mol Endocrinol 29: 23-39.

Calderaro A, Piccolo G, Perandin F, Gorrini C, Peruzzi S, Zuelli C, Ricci L, Manca N, Dettori G, Chezzi C, Snounou G 2007. Genetic polymorphisms influence Plasmodium ovale PCR detection accuracy. J Clin Microbiol 45: 1624-1627.

Carvalho LH, Brandao MG, Santos-Filho D, Lopes JL, Krettli AU 1991. Antimalarial activity of crude extracts from Brazilian plants studied in vivo in Plasmodium berghei-infected mice and in vitro against Plasmodium falciparum in culture. Braz J Med Biol Res 24: 1113-1123.

Dormond L, Jaton-Ogay K, de Vallière S, Genton B, Bille J, Greub G 2010. Multiplex real-time PCR for the diagnosis of malaria: correlation with microscopy. Clin Microbiol Infect 3: 469-475.

Guescini M, Sisti D, Rocchi M, Stocchi L, Stocchi V 2008. A new real-time PCR method to overcome significant quantitative inaccuracy due to slight amplification inhibition. BMC Bioinformatics 9: 326.

Han ET 2013. Loop-mediated isothermal amplification test for the molecular diagnosis of malaria. Expert Rev Mol Diagn 13: 205-218.

Harris I, Sharrock W, Bain L, Gray K, Bobogare A, Boaz L, Lilley K, Krause D, Vallely A, Johnson M, Gatton M, Shanks G, Cheng Q 2010. A large proportion of asymptomatic Plasmodium infections with low and sub-microscopic parasite densities in the low transmission setting of Temotu Province, Solomon Islands: challenges for malaria diagnostics in an elimination setting. Malar J 9: 254.

Hermsen C, Telgt D, Linders E, van de Locht L, Eling W, Mensink E, Sauerwein R 2001. Detection of Plasmodium falciparum malaria parasites in vivo by real-time quantitative PCR. Mol Biochem Parasitol 118: 247-251.

Jelinek T, Proll S, Hess F, Kabagambe G, von Sonnenburg F, Loscher T, Kilian A 1996. Geographic differences in the sensitivity of a polymerase chain reaction for the detection of Plasmodium falciparum infection. Am J Trop Med Hyg 55: 647-651.

Jensen JB 1978. Concentration from continuous culture of erythrocytes infected with trophozoites and schizonts of Plasmodium falciparum. Am J Trop Med Hyg 27: 1274-1276.

Jensen JB, Trager W 1977. Plasmodium falciparum in culture: use of outdated erthrocytes and description of the candle jar method. J Parasitol 63: 883-886.

Karrer E, Lincoln J, Hogenhout S, Bennett A, Bostock R, Martineau B, Lucas W, Gilchrist D, Alexander D 1995. In situ isolation of mRNA from individual plant cells: creation of cell-specific cDNA libraries. Proc Natl Acad Sci USA 92: 3814-3818.

Kimura M, Kaneko O, Liu Q, Kaemoto F, Wataya Y, Otani S, Yamaguchi Y, Tanabe K 1997. Identification of the four species of human malaria parasites by nested PCR that targets variant sequences in the small subunit rRNA gene. Parasitol Int 46: 91-95.

Maciel GBML 2011. Malária e atividades ocupacionais no municipio de Colniza, Mato Grosso, no periodo de 2003 a 2009, MSc Thesis, Universidade Federal do Mato Grosso, Cuiabá, 84 pp. 
Mangold K, Manson R, Koay E, Stephens L, Regner M, Thomson RJ, Peterson L, Kaul K 2005. Real-time PCR for detection and identification of Plasmodium spp. J Clin Microbiol 43: 2435-2440.

malERA - Consultative Group on Diagnoses and Diagnostics 2011. A research agenda for malaria eradication: diagnoses and diagnostics. PLoS Med 8: e1000396.

McMorrow ML, Aidoo M, Kachur SP 2011. Malaria rapid diagnostic tests in elimination settings - can they find the last parasite? Clin Microbiol Infect 17: 1624-1631.

Moreira OC, Ramírez JD, Velázquez E, Melo MF, Lima-Ferreira C, Guhl F, Sosa-Estani S, Marin-Neto JA, Morillo CA, Britto C 2013. Towards the establishment of a consensus real-time qPCR to monitor Trypanosoma cruzi parasitemia in patients with chronic Chagas disease cardiomyopathy: a substudy from the BENEFIT trial. Acta Trop 125: 23-31

Ogutu B, Tiono A, Makanga M, Premji Z, Gbadoé A, Ubben D, Marrast A, Gaye O 2010. Treatment of asymptomatic carriers with artemether-lumefantrine: an opportunity to reduce the burden of malaria? Malar J 9: 30.

Olsson M, Hansson C, Avent N, Akesson I, Green C, Daniels G 1998. A clinically applicable method for determining the three major alleles at the Duffy (FY) blood group locus using polymerase chain reaction with allele-specific primers. Transfusion 38: 168-173.

Parida MM 2008. Rapid and real-time detection technologies for emerging viruses of biomedical importance. J Biosci 33: 617-628.

Proux S, Suwanarusk R, Barends M, Zwang J, Price RN, Leimanis M, Kiricharoen L, Laochan N, Russell B, Nosten F, Snounou G 2011. Considerations on the use of nucleic acid-based amplification for malaria parasite detection. Malar J 10: 323.
Rosanas-Urgell A, Mueller D, Betuela I, Barnadas C, Iga J, Zimmerman PA, del Portillo HA, Siba P, Mueller I, Felger I 2010. Comparison of diagnostic methods for the detection and quantification of the four sympatric Plasmodium species in field samples from Papua New Guinea. Malar J 9: 361.

Singh B, Bobogare A, Cox-Singh J, Snounou G, Abdullah M, Rahman $\mathrm{H}$ 1999. A genus and species-specific nested polymerase chain reaction malaria detection assay for epidemiologic studies. $\mathrm{Am} \mathrm{J}$ Trop Med Hyg 60: 687-692.

Snounou G, Viriyakosol S, Zhu XP, Jarra W, Pinheiro L, do Rosario VE, Thaithong S, Brown KN 1993. High sensitivity of detection of human malaria parasites by the use of nested polymerase chain reaction. Mol Biochem Parasitol 61: 315-320.

Soong R, Ladányi A 2003. Improved indicators for assessing the reliability of detection and quantification by kinetic PCR. Clin Chem 49: 973-976.

Stenman J, Orpana A 2001. Accuracy in amplification. Nat Biotechnol 19: 1011-1012.

Stresman G, Kobayashi T, Kamanga A, Thuma PE, Mharakurwa S, Moss WJ, Shiff C 2012. Malaria research challenges in low prevalence settings. Malar J 11: 353.

Veron V, Simon S, Carme B 2009. Multiplex real-time PCR detection of P. falciparum, P. vivax and P. malariae in human blood samples. Exp Parasitol 121: 346-351.

Win T, Lin K, Mizuno S, Zhou M, Liu Q, Ferreira M, Tantular I, Kojima S, Ishii A, Kawamoto F 2002. Wide distribution of Plasmodium ovale in Myanmar. Trop Med Int Health 7: 231-239. 